\title{
PUBLIC PERCEPTION OF THE ROLE OF PHARMACISTS AND WILLINGNESS TO PAY FOR PHARMACIST-PROVIDED DISPENSING SERVICES: A CROSS-SECTIONAL PILOT STUDY IN THE STATE OF SABAH, MALAYSIA
}

\author{
CHEAH MENG FEI \\ Department of Pharmacy, Hospital Tawau, Peti Surat 67, \\ 91007 Tawau, Sabah, Malaysia
}

Published online: 23 October 2018

To cite this article: CHEAH MENG FEI (2018) Public perception of the role of pharmacists and willingness to pay for pharmacist-provided dispensing services: A cross-sectional pilot study in the state of Sabah, Malaysia, Malaysian Journal of Pharmaceutical Sciences, 16(1): 1-21, https://doi.org/10.21315/mjps2018.16.1.1.

To link to this article: $h$ ttps://doi.org/10.21315/mjps2018.16.1.1

Pharmacists play an important role in healthcare delivery. Over the years, their role has shifted from product-oriented to patient-oriented. This study aimed to assess the perceptions of the public towards the role of pharmacists and the willingness of the public to pay for pharmacist-provided dispensing services in Sabah. This was a questionnairebased, cross-sectional study conducted from September 2014 to June 2015 in three major cities in Sabah, namely, Kota Kinabalu, Sandakan and Tawau. The respondents were conveniently selected and interviewed based on a questionnaire to assess their perceptions of the role of pharmacists. A contingent valuation interview was then conducted to assess the respondents' willingness to pay. A total of 647 respondents were interviewed. Of the respondents, $61.4 \%$ agreed that pharmacists knew more about their medications and side effects and how to use the medications than their doctors. However, more than half of the respondents (54.4\%) perceived that the pharmacists' role was only to supply medications and $66.6 \%$ of the respondents perceived that the pharmacist's role was to follow doctors' directions. Of the respondents, $89.0 \%$ appreciated and adhered to the counselling points provided by their pharmacists; $85.0 \%$ of the respondents hoped that pharmacists could play a greater role in healthcare in the future. Forty percent of the respondents agreed that community pharmacists were simply business people who sold products in their pharmacies. Finally, 55.3\% of the respondents were willing to pay for pharmacist-provided dispensing services. The median (interquartile ranges [IQR]) amount that they were willing to pay was RM5.00 (IQR RM5.00). Respondents in this study showed variations in their views of the pharmacy profession. Nevertheless, more than half of the respondents valued pharmacist-provided dispensing services and were willing to pay RM5.00 for the services. To improve pharmacy practice, efforts should be undertaken to address the respondents' misunderstandings about the pharmacy profession and to promote the roles of pharmacists to the general public.

Keywords: Public perception, Pharmacists, Willingness to pay (WTP), Pharmacist-provided dispensing services

"Corresponding author: mfcheah85@hotmail.com

(C) Penerbit Universiti Sains Malaysia, 2018. This work is licensed under the terms of the Creative Commons Attribution (CC BY) (http://creativecommons.org/licenses/by/4.0/). 


\section{INTRODUCTION}

Pharmacists play an important role in healthcare delivery. A study by Perepelkin (2011) showed that there was a high level of agreement that pharmacists were healthcare professionals, such as physicians and nurses and $75.9 \%$ of the respondents understood what pharmacists were doing (Perepelkin 2011). However, a study conducted by El Hajj, Salem and Mansoor (2011) showed that only $37.0 \%$ of respondents agreed that pharmacists were sufficiently knowledgeable and provided sufficient time to discuss their problems. The study also concluded that the public had poor understanding of the role of pharmacists in monitoring drug therapy, performing health screening and providing drug information (El Hajj, Salem and Mansoor 2011). In addition, a study conducted by Eades, Ferguson and O'Carroll (2011) stated that pharmacists could contribute to public health, but both pharmacists and the public must change their behaviours to ensure that service can be delivered. Hence, it is important for the public to accept that pharmacists play a main role in providing public health services (Eades, Ferguson and O'Carroll 2011). In another study conducted by Tootelian, Rolston and Negrete (2006), which assessed the receptiveness of consumers towards the non-traditional roles of community pharmacists, the authors discovered that, while patient perceptions of and satisfaction with pharmacists were high, there remained inadequacy in terms of knowledge of pharmacists' roles and responsibilities (Tootelian, Rolston and Negrete 2005).

In Malaysia, healthcare is provided by both the public and private sectors. The public healthcare system consists of public hospitals and health clinics and it is mainly subsidised by the government and financed by public tax revenues. Hence, patients must only pay a minimum fee to obtain services. In contrast, the private healthcare system consists of private hospitals and general practitioner (GP) clinics which provide healthcare service based on a fee-for-service basis. Hence, the private healthcare system is currently providing services to people who can afford to pay. Unlike the public healthcare setting, in which the pharmacists possess an important role in the complete control of the supplying of medication, doctors in private hospitals and GP clinics are granted the right to dispense medications. However, a national survey about the use of medicines by Malaysian Consumers 2012 showed that $43.5 \%$ of consumers still did not understand the proper use of their medicines, $50.2 \%$ of them were unaware of trade names and $35.8 \%$ of them were not aware of common side effects of their medications. Patient education and counselling about medications are neglected in the most private healthcare facilities due to the unavailability of pharmacists (Saw et al. 2015).

In Malaysia, pharmacists mainly provide services at public facilities and in community and industrial settings. The community and industrial settings are also referred to as private settings. The current role of pharmacists is not only dispensing at the counter, but it has also been broadened to include providing pharmaceutical care via various services. According to Saw et al. (2015), pharmacists were able to perform medication reviews thoroughly for patients, identify pharmaceutical care issues and provide recommendations and solutions for the administration or compatibility of drugs. In addition, pharmacists were able to educate patients about medication compliance and device handling techniques and counsel them on healthcare matters (Saw et al. 2015). Hence, pharmacists are able to provide professional services that can alleviate medication-related concerns.

Prescribing and dispensing are two important tasks in patients' treatment. Because of the complexities and distinctly separate nature of these tasks, separate roles of doctors as prescribers and pharmacists as dispensers have been implemented in many countries. In Asia, Japan, Taiwan, South Korea, Indonesia, India and the Philippines have gradually separated dispensing and prescribing roles. Malaysia, one of the few countries

Malay J Pharm Sci, Vol. 16, No. 1 (2018): 1-21 
where physician dispensing practices are still allowed, especially in the private setting, has been anticipating a separation of roles for many decades. However, issues such as the inadequacy of pharmacists and objections from various parties have hindered progress towards dispensing separation (Shafie et al. 2012). Nevertheless, a pilot study exploring the perceptions of GPs towards professional training and the roles of community pharmacists suggested that they would support an extension of the role of the community pharmacists in patient care activities, such as medication counselling (Hassali et al. 2009). In addition, a study conducted among the Malaysian public found that $67.0 \%$ of respondents were willing to fill their prescriptions in pharmacies and appreciated the value of pharmacists in detecting possible medication errors and identifying drug interactions and polypharmacy (Saw et al. 2015; Shafie and Hassali 2010).

To date, pharmacists in Malaysia do not charge customers dispensing fees. However, in most countries that have implemented dispensing separation, dispensing service fees have been set as percentage mark-up systems or fees for service based on government negotiation or previous utilisation rates. A dispensing fee chargeable to customers was proposed to pay for the professional services provided by pharmacists (Huttin 1996). A study conducted in the state of Pulau Pinang, Malaysia, by Shafie and Hassali (2011) showed that the mean dispensing cost per minute was RM0.41 and assuming that the dispensing time was 10 or 15 minutes, the dispensing costs per prescription were RM4.10 or RM6.15, respectively (Shafie and Hassali 2011).

In terms of willingness to pay (WTP) for pharmacist-provided services, various studies have been published in many countries to assess this matter. However, most of these studies have only evaluated a specific or expanded pharmacy service rather than basic dispensing services. In addition, these studies have been based in countries where dispensing separation was well established. One of the studies in Malaysia was conducted in the state of Pulau Pinang by Shafie and Hassali (2010), showing that $67.0 \%$ of respondents were willing to pay for pharmacist-provided dispensing services. The median (interquartile ranges [IQR]) amount that the respondents were willing to pay for a community pharmacist's dispensing services was RM10.00 (RM8.00, RM16.00). In addition, correlation testing from the study also showed that the WTP amount for pharmacist-provided dispensing services was moderately correlated $(r=0.377, p=0.02)$ with the respondents' knowledge of community pharmacists' dispensing services (Shafie and Hassali 2010). However, Saw et al. (2015) concluded that a small group of respondents was concerned that the total cost of treatment would increase if dispensing separation became the official policy because patients would need to pay both the doctor consultation fee and the pharmacist dispensing fee. Hence, the majority of the respondents were not willing to pay an additional cost of treatment due to the dispensing separation policy (Saw et al. 2015).

Knowing the expanded roles of pharmacists in Malaysia and the insufficiency of studies conducted in Malaysia to evaluate public perceptions of pharmacists, this study was conducted to understand better the public perceptions of pharmacists and the acceptance of the expanded roles of pharmacists in the state of Sabah, Malaysia. In addition, due to the relatively lower socioeconomic status of the state of Sabah compared to its counterparts in Peninsular Malaysia, this study also assessed the public WTP for pharmacist-provided dispensing services among the general population in the state of Sabah, Malaysia. 


\section{METHODOLOGY}

\section{Study Design}

This was a questionnaire-based, cross-sectional study conducted from September 2014 to June 2015 in three major cities in Sabah, Malaysia, namely Kota Kinabalu, Sandakan and Tawau.

\section{Sample Selection and Sample Size}

The respondents in this study were the general populations of Kota Kinabalu, Sandakan and Tawau. Based on sample size calculation, the minimum sample size required for this study was 562 . This figure was arrived at by assuming a $95 \%$ likelihood of the estimate being within $\pm 5 \%$ of the true proportion, assuming as well that $75.9 \%$ of the respondents understood the roles of pharmacists based on a literature review (Perepelkin 2011) and assuming the design effects to be approximately 2 due to the nature of respondent-driven sampling. Since we used the interview method, the response rate was expected to be $100 \%$. For ease of sampling, the researchers planned to target 630 respondents.

The 630 respondents were planned to be selected via convenience sampling from the aforementioned three cities, with 210 respondents from each city. Since the researchers targeted respondents from public hospital pharmacies, community pharmacies and the general public, 70 respondents were conveniently sampled from each of the strata for a total of 210 respondents from each city.

The selected respondents had to be 18 years of age or older, with no cognitive disabilities and the ability to read and communicate in Malay, English or Chinese.

\section{Ethical Approval}

This study was approved by Medical Research and Ethics Committee (MREC) of the Ministry of Health (MOH) of Malaysia via the National Medical Research Registry (NMRR) under registration number NMRR-14-206-19230. All of the responses obtained from the interviews remained confidential and respondents were allowed to refuse participation in the study.

\section{Recruitment Procedure}

A total of 30 pharmacists working in public hospitals and health clinics in Sabah (13 from Kota Kinabalu, 7 from Sandakan and 10 from Tawau) were selected as interviewers and data collectors. All of the researchers were briefed about the study prior to data collection for the purpose of standardisation of the methodology used throughout the data collection process. This process was undertaken to ensure that neither misinterpretation nor misunderstanding of the study questions that might result in bias occurred.

All eligible respondents, in the outpatient pharmacies of public hospitals or health clinics, in community pharmacies or in the general public, were approached by the researchers. Those respondents who agreed to participate were informed about the purpose of the study and verbal consent was obtained. The respondents were interviewed by the researchers on a one-to-one basis for approximately 30 minutes based on a questionnaire.

Malay J Pharm Sci, Vol. 16, No. 1 (2018): 1-21 


\section{Questionnaire}

A questionnaire was developed by the researchers based on a literature review and group discussion and was then validated for its content by five experts who had more than three years of experience in pharmacy practice. The questionnaire was also translated into Malay and pretested among 10 respondents for clarity, relevance, acceptability and time for completion prior to the actual study. Following pretesting, revision and slight modification to the questionnaire were performed.

The questionnaire was divided into six key sections: Section A collected patients' demographic information (age, gender, race, occupation, education level and household income), Section B assessed the nature and frequency of pharmacy service utilisation in both public and community settings, Section $\mathrm{C}$ (nine items) assessed the public perceptions of the roles of pharmacists, Section $D$ (four items) evaluated the factors influencing perceptions of pharmacists, Section E (seven items) evaluated access to community pharmacies and Section F assessed the WTP for pharmacist-provided dispensing services. The answers to all of the items in Sections $C$, D and E were scored on a 5-point Likert scale ( 1 = strongly disagree, 2 = disagree, 3 = neutral, $4=$ agree, $5=$ strongly agree). A "don't know" response was also included for all of the questions.

To assess WTP in Section F, contingent valuation interviews were conducted. The contingent valuation (CV) method was applied using a bidding game approach via face-to-face interviews with the respondents. The respondents were presented with a description of the differences in prescribing and dispensing activities, pharmacists' roles in dispensing service, the risk of medication errors in prescriptions and their consequences, the involvement of pharmacists' interventions in reducing the risk of medication errors and a hypothetical scenario in which dispensing separation was implemented in a community pharmacy setting in Malaysia. The respondents were then asked a series of questions regarding their WTP for the pharmacist-provided dispensing service to compensate for the professional service provided by pharmacists and the maximum amount that they were willing to pay. The bidding was initiated with an initial value of RM5.00. If the respondent agreed to pay that value, the amount that he or she was willing to pay was increased by RM5.00 to RM10.00. If the respondent further agreed to pay RM10.00, the amount he or she willing to pay was further increased by RM5.00 to the maximum of RM15.00. If the respondent was still willing to pay the maximum value of RM15.00, an open-ended question was asked to obtain the maximum amount the respondent was willing to pay for the pharmacist-provided dispensing service. However, if the respondent refused to pay the initial bidding amount of RM5.00, a reduction of RM1.00 was offered every time the participant refused to pay for the service. The bidding amount was reduced until an agreed amount was obtained.

\section{Data Analysis}

Data analysis was performed using IBM SPSS software, version 22.0 (IBM Corporation, Armonk, New York, USA). Demographic information about the respondents, the nature and frequency of service utilisation of pharmacists, public perceptions of the roles of pharmacists, factors influencing perceptions of pharmacists, access to community pharmacies and the WTP for pharmacist-provided dispensing services were analysed descriptively either in percentages or medians (IQRs). The chi-square test or Fisher's exact test was employed to assess the factors associated with respondents' WTP. The Mann-Whitney $U$ test or the 
Kruskal-Wallis test was employed to assess the factors associated with the amount that the respondents were willing to pay for pharmacist-provided dispensing services. For all of the statistical tests performed, the significance level was set a priori at $p<0.05$.

\section{RESULTS}

For this study, a total of 647 respondents were interviewed (response rate $100 \%$ ). A total of $210(32.5 \%)$ of the respondents were from Kota Kinabalu, $215(33.2 \%)$ were from Sandakan and the remaining $222(34.3 \%)$ were from Tawau. In terms of strata, $217(33.5 \%)$ of the respondents were targeted from public facilities (public hospitals or health clinics), $213(32.9 \%)$ were targeted from community pharmacies and the remaining $217(33.5 \%)$ were targeted from the general public.

\section{Demographic Characteristics}

The demographic characteristics of the respondents are shown in Table 1. More than half of the respondents $(56.1 \%)$ were female. The median age was 36 years old, with and interquartile range of 21 years. Most of the respondents $(48.7 \%)$ were between 18 and 35 years old. Of the respondents, $39.6 \%$ were Sabah natives and had a secondary level of education (49.5\%). In terms of occupation, the majority of them $(43.4 \%)$ were non-professional, non-manual workers. The monthly household income for most of the respondents $(40.6 \%)$ was at least $\mathrm{RM} 2,000$.

Table 1: Demographic and clinical characteristics of the respondents $(N=647)$.

\begin{tabular}{ll}
\hline Characteristics & Frequency (\%) \\
\hline Sex & \\
$\quad$ Male & $284(43.9)$ \\
Female & $363(56.1)$ \\
Age & \\
$18-35$ & $315(48.7)$ \\
$36-50$ & $199(30.8)$ \\
$>50$ & $133(20.6)$ \\
Race & \\
Sabah natives & $256(39.6)$ \\
Malay & $116(17.9)$ \\
Chinese & $176(27.2)$ \\
Indian & $7(1.1)$ \\
Others & $92(14.2)$ \\
Highest education level & \\
Primary & \\
Secondary & $64(9.9)$ \\
Tertiary & $320(49.5)$ \\
Have not attended school & $248(38.3)$ \\
\hline
\end{tabular}

(continued on next page)

Malay J Pharm Sci, Vol. 16, No. 1 (2018): 1-21 
Table 1: (continued)

\begin{tabular}{ll}
\hline Characteristics & Frequency (\%) \\
\hline Occupation & \\
Professional & $111(17.2)$ \\
Non-professional, non-manual worker & $281(43.4)$ \\
Manual worker & $66(10.2)$ \\
Student & $40(6.2)$ \\
Housewife & $67(10.4)$ \\
Unemployed & $46(7.1)$ \\
Retiree & $36(5.6)$ \\
Monthly household income (RM) & \\
$<500$ & $24(3.7)$ \\
$500-999$ & $101(15.6)$ \\
$1,000-1,999$ & $173(26.7)$ \\
$\geq 2,000$ & $263(40.6)$ \\
No income & $86(13.3)$ \\
\hline
\end{tabular}

\section{Nature and Frequency of Pharmacy Service Utilisation}

Among the 647 respondents interviewed, only two of them $(0.3 \%)$ had never visited a pharmacy. The nature and frequency of pharmacy service utilisation in both public and community settings for those respondents who had visited a pharmacy prior to the study are shown in Table 2. Among the 645 respondents, a majority of them (72.6\%) had visited pharmacies in both public facilities and community settings prior to the study. Ninety of the respondents $(14.0 \%)$ had never visited any pharmacies in the public facilities, while another 87 of them $(13.5 \%)$ had never visited any community pharmacies. In terms of frequency of pharmacy visits, a majority of the respondents had visited pharmacies in both public facilities and community settings once every few months (48.7\% and $46.5 \%$, respectively). A majority of the respondents visited pharmacies to collect medications $(76.3 \%)$ or to purchase medications (69.9\%). However, $39.5 \%$ of the respondents were found only to accompany their family members to pharmacies.

\section{Public Perceptions of the Roles of Pharmacists}

Table 3 summarises the respondents' perceptions of the roles of pharmacists. Of the respondents, $47.2 \%$ had no difficulty in distinguishing between pharmacists and other healthcare professionals. A majority of the respondents (89.0\%) agreed that pharmacists' main job was to inform consumers about how to use their medications and to warn them of any possible side effects. In addition, $61.4 \%$ of the respondents agreed that pharmacists knew more about their medications and side effects and how to use the medications than their doctors. However, more than half of the respondents $(54.4 \%)$ perceived that the pharmacists' role was only to supply medications and $66.6 \%$ of the respondents perceived that the pharmacists' job was to follow doctors' directions. Only $41.9 \%$ of the respondents agreed that pharmacists were allowed to intervene and modify prescriptions and $12.4 \%$ of the respondents were not aware of this role that pharmacists could play. Based on the interviews, $89.0 \%$ of the respondents appreciated and adhered to the counselling points provided by their pharmacists. In addition, $85.0 \%$ of the respondents hoped that pharmacists 
could play greater roles in healthcare in the future. However, when asked about whether community pharmacists were simply businesspeople who sold products in their pharmacies, most of the respondents $(40.0 \%)$ agreed.

Table 2: Nature and frequency of pharmacy service utilisation $(N=645)$.

\begin{tabular}{ll}
\hline Item & Frequency (\%) \\
\hline Frequency of public pharmacy visits & \\
Never & $90(14.0)$ \\
Once or more per week & $14(2.2)$ \\
$2-3$ times per month & $105(16.3)$ \\
Every few months & $314(48.7)$ \\
Once per year & $122(18.9)$ \\
Frequency of community pharmacy visits & \\
Never & \\
Once or more per week & $87(13.5)$ \\
$2-3$ times per month & $33(5.1)$ \\
Every few months & $123(19.1)$ \\
Once a year & $300(46.5)$ \\
Reason for visiting pharmacy & $102(15.8)$ \\
For medication collection & \\
Counselling on devices and disease management & \\
Pharmacy exhibition/booth & $492(76.3)$ \\
Admitted to ward & $98(15.2)$ \\
Accompanying family members & $34(5.3)$ \\
To purchase medications & $68(10.5)$ \\
To purchase medical devices/equipment & $255(39.5)$ \\
To buy non-medical products (e.g., cosmetics, toiletries and confectionery) & $451(69.9)$ \\
For simple check-ups, e.g., blood glucose tests & $184(28.5)$ \\
Other & $178(27.6)$ \\
\hline
\end{tabular}

Table 3: Perceptions of the roles of pharmacists $(N=647)$.

\begin{tabular}{|c|c|c|c|c|c|c|}
\hline \multirow[b]{2}{*}{ Item } & \multicolumn{6}{|c|}{ Frequency (\%) } \\
\hline & $\begin{array}{l}\text { Strongly } \\
\text { disagree }\end{array}$ & Disagree & Neutral & Agree & $\begin{array}{l}\text { Strongly } \\
\text { agree }\end{array}$ & $\begin{array}{l}\text { Don't } \\
\text { know }\end{array}$ \\
\hline $\begin{array}{l}\text { I have difficulty in distinguishing } \\
\text { between the pharmacist and other } \\
\text { healthcare professionals. }\end{array}$ & $\begin{array}{c}67 \\
(10.4)\end{array}$ & $\begin{array}{c}238 \\
(36.8)\end{array}$ & $\begin{array}{c}89 \\
(13.8)\end{array}$ & $\begin{array}{c}180 \\
(27.8)\end{array}$ & $\begin{array}{c}41 \\
(6.3)\end{array}$ & $\begin{array}{c}32 \\
(4.9)\end{array}$ \\
\hline $\begin{array}{l}\text { The pharmacist's role is only to } \\
\text { supply medications. }\end{array}$ & $\begin{array}{c}31 \\
(4.8)\end{array}$ & $\begin{array}{c}190 \\
(29.4)\end{array}$ & $\begin{array}{c}61 \\
(9.4)\end{array}$ & $\begin{array}{c}282 \\
(43.6)\end{array}$ & $\begin{array}{c}70 \\
(10.8)\end{array}$ & $\begin{array}{c}13 \\
(2.0)\end{array}$ \\
\hline $\begin{array}{l}\text { My pharmacist's main job is to help } \\
\text { me learn how to use my medication } \\
\text { and to warn me of any possible side } \\
\text { effects. }\end{array}$ & $\begin{array}{c}5 \\
(0.8)\end{array}$ & $\begin{array}{c}22 \\
(3.4)\end{array}$ & $\begin{array}{c}34 \\
(5.3)\end{array}$ & $\begin{array}{c}359 \\
(55.5)\end{array}$ & $\begin{array}{c}217 \\
(33.5)\end{array}$ & $\begin{array}{c}10 \\
(1.5)\end{array}$ \\
\hline $\begin{array}{l}\text { It is a pharmacist's job to follow my } \\
\text { doctor's directions. }\end{array}$ & $\begin{array}{c}8 \\
(1.2)\end{array}$ & $\begin{array}{c}79 \\
(12.2)\end{array}$ & $\begin{array}{c}97 \\
(15.0)\end{array}$ & $\begin{array}{c}316 \\
(48.8)\end{array}$ & $\begin{array}{c}115 \\
(17.8)\end{array}$ & $\begin{array}{c}32 \\
(4.9)\end{array}$ \\
\hline
\end{tabular}

Malay J Pharm Sci, Vol. 16, No. 1 (2018): 1-21 
Table 3: (continued)

\begin{tabular}{|c|c|c|c|c|c|c|}
\hline \multirow[b]{2}{*}{ Item } & \multicolumn{6}{|c|}{ Frequency (\%) } \\
\hline & $\begin{array}{l}\text { Strongly } \\
\text { disagree }\end{array}$ & Disagree & Neutral & Agree & $\begin{array}{c}\text { Strongly } \\
\text { agree }\end{array}$ & $\begin{array}{l}\text { Don't } \\
\text { know }\end{array}$ \\
\hline $\begin{array}{l}\text { My pharmacist knows more about } \\
\text { my medicine and its side effects and } \\
\text { how to use it than my doctor. }\end{array}$ & $\begin{array}{c}18 \\
(2.8)\end{array}$ & $\begin{array}{c}81 \\
(12.5)\end{array}$ & $\begin{array}{c}118 \\
(18.2)\end{array}$ & $\begin{array}{c}273 \\
(42.2)\end{array}$ & $\begin{array}{c}124 \\
(19.2)\end{array}$ & $\begin{array}{c}33 \\
(5.1)\end{array}$ \\
\hline $\begin{array}{l}\text { Pharmacists are allowed } \\
\text { to intervene and to modify } \\
\text { prescriptions. }\end{array}$ & $\begin{array}{c}53 \\
(8.2)\end{array}$ & $\begin{array}{c}148 \\
(22.9)\end{array}$ & $\begin{array}{c}95 \\
(14.7)\end{array}$ & $\begin{array}{c}214 \\
(33.1)\end{array}$ & $\begin{array}{c}57 \\
(8.8)\end{array}$ & $\begin{array}{c}80 \\
(12.4)\end{array}$ \\
\hline $\begin{array}{l}\text { I hope that my pharmacist can play } \\
\text { a greater role in healthcare in the } \\
\text { future. }\end{array}$ & $\begin{array}{c}7 \\
(1.1)\end{array}$ & $\begin{array}{c}17 \\
(2.6)\end{array}$ & $\begin{array}{c}58 \\
(9.0)\end{array}$ & $\begin{array}{c}376 \\
(58.1)\end{array}$ & $\begin{array}{c}174 \\
(26.9)\end{array}$ & $\begin{array}{c}15 \\
(2.3)\end{array}$ \\
\hline $\begin{array}{l}\text { I appreciate and adhere to the } \\
\text { counselling points provided by my } \\
\text { pharmacist. }\end{array}$ & $\begin{array}{c}3 \\
(0.5)\end{array}$ & $\begin{array}{c}10 \\
(1.5)\end{array}$ & $\begin{array}{c}53 \\
(8.2)\end{array}$ & $\begin{array}{c}398 \\
(61.5)\end{array}$ & $\begin{array}{c}178 \\
(27.5)\end{array}$ & $\begin{array}{c}5 \\
(0.8)\end{array}$ \\
\hline $\begin{array}{l}\text { Pharmacists in community/private } \\
\text { settings are simply businesspeople } \\
\text { who sell products in a pharmacy. }\end{array}$ & $\begin{array}{c}48 \\
(7.4)\end{array}$ & $\begin{array}{c}180 \\
(27.8)\end{array}$ & $\begin{array}{c}130 \\
(20.1)\end{array}$ & $\begin{array}{c}204 \\
(31.5)\end{array}$ & $\begin{array}{c}55 \\
(8.5)\end{array}$ & $\begin{array}{c}30 \\
(4.6)\end{array}$ \\
\hline
\end{tabular}

\section{Factors Influencing Perceptions of Pharmacists}

Table 4 summarises the factors influencing respondents' perceptions of pharmacists. Generally, all four of the factors were influential. The most influential factor was the friendliness of the pharmacists $(89.4 \%)$, while the least influential was a waiting time of less than 30 minutes $(76.1 \%)$.

Table 4: Factors influencing perceptions of pharmacists $(\mathrm{N}=647)$.

\begin{tabular}{lcccccc}
\hline \multirow{2}{*}{ Item } & \multicolumn{7}{c}{ Frequency (\%) } \\
\cline { 2 - 7 } & $\begin{array}{l}\text { Strongly } \\
\text { disagree }\end{array}$ & Disagree & Neutral & Agree & $\begin{array}{c}\text { Strongly } \\
\text { agree }\end{array}$ & $\begin{array}{c}\text { Don't } \\
\text { know }\end{array}$ \\
\hline Friendliness & 2 & 9 & 53 & 349 & 230 & 4 \\
Expertise & $(0.3)$ & $(1.4)$ & $(8.2)$ & $(53.9)$ & $(35.5)$ & $(0.6)$ \\
& 3 & 12 & 49 & 325 & 249 & 9 \\
Environment and facilities & $(0.5)$ & $(1.9)$ & $(7.6)$ & $(50.2)$ & $(38.5)$ & $(1.4)$ \\
of the pharmacy & 3 & 18 & 71 & 347 & 198 & 10 \\
Waiting time less than & $(0.5)$ & $(2.8)$ & $(11.0)$ & $(53.6)$ & $(30.6)$ & $(1.5)$ \\
30 minutes & 7 & 53 & 83 & 278 & 214 & 12 \\
& $(1.1)$ & $(8.2)$ & $(12.8)$ & $(43.0)$ & $(33.1)$ & $(1.9)$ \\
\hline
\end{tabular}

\section{Access to Community Pharmacies}

Table 5 summarises respondents' opinions about community pharmacies. Three major factors that influenced whether a respondent would visit a community pharmacy or not were identified. These factors were the expertise of the community pharmacist $(92.2 \%)$, 
whether the community pharmacy was located in a strategic location or not (89.5\%) and the attitudes of the community pharmacist and other staff in the pharmacy $(89.0 \%)$. Only $73.3 \%$ of the respondents agreed that community pharmacies that offer lower prices would be their preference. However, more than half of the respondents $(51.4 \%)$ felt that the hours of operation for community pharmacies from 8:00 a.m. to 5:00 p.m. were not sufficient.

Table 5: Access to community pharmacies $(N=647)$.

\begin{tabular}{|c|c|c|c|c|c|c|}
\hline \multirow[b]{2}{*}{ Item } & \multicolumn{6}{|c|}{ Frequency (\%) } \\
\hline & $\begin{array}{l}\text { Strongly } \\
\text { disagree }\end{array}$ & Disagree & Neutral & Agree & $\begin{array}{l}\text { Strongly } \\
\text { agree }\end{array}$ & $\begin{array}{l}\text { Don't } \\
\text { know }\end{array}$ \\
\hline $\begin{array}{l}\text { Community pharmacies should be } \\
\text { opened in strategic locations. }\end{array}$ & $\begin{array}{c}1 \\
(0.2)\end{array}$ & $\begin{array}{c}14 \\
(2.2)\end{array}$ & $\begin{array}{c}39 \\
(6.0)\end{array}$ & $\begin{array}{c}351 \\
(54.3)\end{array}$ & $\begin{array}{c}228 \\
(35.2)\end{array}$ & $\begin{array}{c}14 \\
(2.2)\end{array}$ \\
\hline $\begin{array}{l}\text { The pharmacy has a list of all of the } \\
\text { personal medications that I need. }\end{array}$ & $\begin{array}{c}5 \\
(0.8)\end{array}$ & $\begin{array}{l}56 \\
(8.7)\end{array}$ & $\begin{array}{c}88 \\
(13.6)\end{array}$ & $\begin{array}{c}308 \\
(47.6)\end{array}$ & $\begin{array}{c}154 \\
(23.8)\end{array}$ & $\begin{array}{c}36 \\
(5.6)\end{array}$ \\
\hline $\begin{array}{l}\text { The community pharmacies that } \\
\text { I visit should offer a variety of } \\
\text { consumer products (non-health- } \\
\text { related). }\end{array}$ & $\begin{array}{c}24 \\
(3.7)\end{array}$ & $\begin{array}{c}131 \\
(20.2)\end{array}$ & $\begin{array}{c}106 \\
(16.4)\end{array}$ & $\begin{array}{c}272 \\
(42.0)\end{array}$ & $\begin{array}{c}82 \\
(12.7)\end{array}$ & $\begin{array}{c}32 \\
(4.9)\end{array}$ \\
\hline $\begin{array}{l}\text { The pharmacist in the pharmacy } \\
\text { must have expertise. }\end{array}$ & $\begin{array}{c}2 \\
(0.3)\end{array}$ & $\begin{array}{c}1 \\
(0.2)\end{array}$ & $\begin{array}{c}34 \\
(5.3)\end{array}$ & $\begin{array}{c}325 \\
(50.2)\end{array}$ & $\begin{array}{c}272 \\
(42.0)\end{array}$ & $\begin{array}{c}13 \\
(2.0)\end{array}$ \\
\hline $\begin{array}{l}\text { The attitude of the pharmacist and } \\
\text { other staff would be of concern to } \\
\text { me. }\end{array}$ & $\begin{array}{c}3 \\
(0.5)\end{array}$ & $\begin{array}{c}9 \\
(1.4)\end{array}$ & $\begin{array}{c}50 \\
(7.7)\end{array}$ & $\begin{array}{c}338 \\
(52.2)\end{array}$ & $\begin{array}{c}238 \\
(36.8)\end{array}$ & $\begin{array}{c}9 \\
(1.4)\end{array}$ \\
\hline $\begin{array}{l}\text { Community pharmacies that } \\
\text { offer lower prices would be my } \\
\text { preference. }\end{array}$ & $\begin{array}{c}14 \\
(2.2)\end{array}$ & $\begin{array}{c}67 \\
(10.4)\end{array}$ & $\begin{array}{c}76 \\
(11.7)\end{array}$ & $\begin{array}{c}280 \\
(43.3)\end{array}$ & $\begin{array}{c}194 \\
(30.0)\end{array}$ & $\begin{array}{c}16 \\
(2.5)\end{array}$ \\
\hline $\begin{array}{l}\text { The open hours for community } \\
\text { pharmacies from } 8 \text { a.m. to } 5 \text { p.m. } \\
\text { are sufficient. }\end{array}$ & $\begin{array}{c}81 \\
(12.5)\end{array}$ & $\begin{array}{c}252 \\
(38.9)\end{array}$ & $\begin{array}{c}71 \\
(11.0)\end{array}$ & $\begin{array}{c}161 \\
(24.9)\end{array}$ & $\begin{array}{c}63 \\
(9.7)\end{array}$ & $\begin{array}{c}19 \\
(2.9)\end{array}$ \\
\hline
\end{tabular}

\section{Willingness to Pay (WTP) for Pharmacist-provided Dispensing Services}

Of the respondents interviewed, 358 of them (55.3\%) were willing to pay for pharmacistprovided dispensing services. Four factors showed statistically significant associations with respondents' WTP (Tables 6 and 7$)$, namely education level $(p=0.011)$, monthly household income $(p=0.023)$, the nature of the pharmacy visit $(p=0.001)$ and the frequency of community pharmacy visits $(p<0.001)$. Other than these factors, WTP was found to be similar across all of the other factors.

The median (IQR) amount that the respondents were willing to pay for pharmacistprovided dispensing services was RM5.00 (RM5.00). Four factors showed statistically significant associations with the amount that the respondents were willing to pay (Table 8), namely city of residence $(p=0.002)$, occupation $(p=0.026)$, monthly household income $(p=0.014)$ and frequency of community pharmacy visits $(p=0.040)$. Other than these factors, the amount that the respondents were willing to pay was found to be similar across all of the other factors. 
Table 6: Factors associated with the participants' WTP $(N=647)$.

\begin{tabular}{|c|c|c|c|}
\hline \multirow{2}{*}{ Variable } & \multicolumn{2}{|c|}{ Frequency (\%) } & \multirow{2}{*}{$p$-value } \\
\hline & Willing to pay & Not willing to pay & \\
\hline City & & & $>0.95^{a}$ \\
\hline Kota Kinabalu & $116(55.2)$ & $94(44.8)$ & \\
\hline Sandakan & $119(55.3)$ & $96(44.7)$ & \\
\hline Tawau & $123(55.4)$ & 99 (44.6) & \\
\hline Age & & & $0.211^{a}$ \\
\hline $18-35$ & $183(58.1)$ & $132(41.9)$ & \\
\hline $36-50$ & $100(50.3)$ & $99(49.7)$ & \\
\hline$>50$ & $75(56.4)$ & $58(43.6)$ & \\
\hline Sex & & & $0.982^{\mathrm{a}}$ \\
\hline Male & $157(55.3)$ & $127(44.7)$ & \\
\hline Female & $201(55.4)$ & $162(44.6)$ & \\
\hline Race & & & $0.509^{a}$ \\
\hline Sabah natives & $138(53.9)$ & $118(46.1)$ & \\
\hline Malay & $63(54.3)$ & $53(45.7)$ & \\
\hline Chinese & $97(55.1)$ & 79 (44.9) & \\
\hline Indian & $6(85.7)$ & $1(14.3)$ & \\
\hline Others & $54(58.7)$ & $38(41.3)$ & \\
\hline Highest education level & & & $0.011^{a}$ \\
\hline Primary & $33(51.6)$ & $31(48.4)$ & \\
\hline Secondary & $162(50.6)$ & $158(49.4)$ & \\
\hline Tertiary & 157 (63.3) & $91(36.7)$ & \\
\hline Have not attended school & $6(40.0)$ & $9(60.0)$ & \\
\hline Occupation & & & $0.476^{\mathrm{a}}$ \\
\hline Professional & $69(62.2)$ & $42(27.8)$ & \\
\hline Non-professional, non-manual worker & $155(55.2)$ & $126(44.8)$ & \\
\hline Manual worker & $34(51.5)$ & $32(48.5)$ & \\
\hline Student & $25(62.5)$ & $15(37.5)$ & \\
\hline Housewife & $36(53.7)$ & $31(46.3)$ & \\
\hline Unemployed & $21(45.7)$ & $25(54.3)$ & \\
\hline Retired & $18(50.0)$ & $18(50.0)$ & \\
\hline Household income (RM) & & & $0.023^{a}$ \\
\hline$<500$ & $9(37.5)$ & $15(62.5)$ & \\
\hline 500-999 & $57(56.4)$ & $44(43.6)$ & \\
\hline $1,000-1,999$ & $84(48.6)$ & $89(51.4)$ & \\
\hline$\geq 2000$ & $163(62.0)$ & $100(38.0)$ & \\
\hline No income & $45(52.3)$ & $41(47.7)$ & \\
\hline Pharmacy visit experience & & & $0.199^{\mathrm{b}}$ \\
\hline Yes & $358(55.5)$ & $287(44.5)$ & \\
\hline No & $0(0.0)$ & $2(100.0)$ & \\
\hline
\end{tabular}

Notes: a Chi-square test, ${ }^{\mathrm{b}}$ Fisher's exact test 
Table 7: Factors associated with the participants' WTP for those who had visited a pharmacy prior to the study $(N=645)$.

\begin{tabular}{lccc}
\hline \multirow{2}{*}{ Variable } & \multicolumn{2}{c}{ Frequency (\%) } & \\
\cline { 2 - 3 } & Willing to pay & Not willing to pay & \\
\hline Nature of pharmacies visited & & & 0.001 \\
$\quad$ Pharmacies in public facilities & $34(39.1)$ & $53(60.9)$ & \\
Community pharmacies & $44(48.9)$ & $46(51.1)$ & \\
$\quad$ Both & $280(59.8)$ & $188(40.2)$ & \\
Frequency of public pharmacy visits & & & 0.599 \\
$\quad$ Never & $44(48.9)$ & $46(51.1)$ & \\
Once or more per week & $9(64.3)$ & $5(35.7)$ & \\
$2-3$ times per month & $62(59.0)$ & $43(41.0)$ & \\
Every few months & $173(55.1)$ & $141(44.9)$ & \\
Once per year & $70(57.4)$ & $52(42.6)$ & \\
Frequency of community pharmacy visits & & & \\
Never & $34(39.1)$ & $53(60.9)$ & \\
Once or more per week & $20(60.6)$ & $13(39.4)$ & \\
$2-3$ times per month & $81(65.9)$ & $42(34.1)$ & \\
Every few months & $176(58.7)$ & $124(41.3)$ & \\
Once per year & $47(46.1)$ & $55(53.9)$ & \\
\hline
\end{tabular}

Notes: a Chi-square test

Table 8: Factors associated with the amount the participants are willing to pay for pharmacist-provided dispensing services $(N=358)$.

\begin{tabular}{|c|c|c|c|c|c|}
\hline \multirow{2}{*}{ Variable } & \multirow{2}{*}{$\begin{array}{c}\text { Frequency } \\
(\%)\end{array}$} & \multicolumn{3}{|c|}{ WTP (RM) } & \multirow{2}{*}{$p$-value } \\
\hline & & Min & Max & Median (IQR) & \\
\hline City & & & & & $0.002^{a}$ \\
\hline Kota Kinabalu & $116(32.4)$ & 1.00 & 50.00 & $5.00(2.25)$ & \\
\hline Sandakan & 119 (33.2) & 1.00 & 100.00 & $5.00(5.00)$ & \\
\hline Tawau & $123(34.4)$ & 1.00 & 50.00 & $5.00(5.00)$ & \\
\hline Age & & & & & $0.355^{a}$ \\
\hline $18-35$ & $183(51.1)$ & 1.00 & 50.00 & $5.00(5.00)$ & \\
\hline $36-50$ & $100(27.9)$ & 1.00 & 100.00 & $5.00(5.00)$ & \\
\hline$>50$ & 75 (20.9) & 1.00 & 50.00 & $5.00(5.00)$ & \\
\hline Sex & & & & & $0.789^{b}$ \\
\hline Male & 157 (43.9) & 1.00 & 50.00 & $5.00(5.00)$ & \\
\hline Female & 201 (56.1) & 1.00 & 100.00 & $5.00(5.00)$ & \\
\hline Race & & & & & $0.073^{a}$ \\
\hline Sabah natives & $138(38.5)$ & 1.00 & 100.00 & $5.00(5.00)$ & \\
\hline Malay & $63(17.6)$ & 1.00 & 50.00 & $5.00(10.00)$ & \\
\hline Chinese & $97(27.1)$ & 1.00 & 50.00 & $5.00(5.00)$ & \\
\hline Indian & $6(1.7)$ & 2.00 & 10.00 & $5.00(2.00)$ & \\
\hline Others & $54(15.1)$ & 1.00 & 30.00 & $5.00(5.25)$ & \\
\hline
\end{tabular}


Table 8: (continued)

\begin{tabular}{|c|c|c|c|c|c|}
\hline \multirow{2}{*}{ Variable } & \multirow{2}{*}{$\begin{array}{l}\text { Frequency } \\
\quad(\%)\end{array}$} & \multicolumn{3}{|c|}{ WTP (RM) } & \multirow{2}{*}{$p$-value } \\
\hline & & Min & Max & $\overline{\text { Median (IQR) }}$ & \\
\hline Highest education level & & & & & $0.264^{a}$ \\
\hline Primary & $33(9.2)$ & 1.00 & 50.00 & $5.00(7.00)$ & \\
\hline Secondary & $162(45.3)$ & 1.00 & 100.00 & $5.00(5.00)$ & \\
\hline Tertiary & $157(43.9)$ & 1.00 & 50.00 & $5.00(5.00)$ & \\
\hline Have not attended school & $6(1.7)$ & 1.00 & 10.00 & $5.00(3.75)$ & \\
\hline Occupation & & & & & $0.026^{a}$ \\
\hline Professional & $69(19.3)$ & 1.00 & 100.00 & $5.00(7.50)$ & \\
\hline Non-professional, non-manual worker & $155(43.3)$ & 1.00 & 50.00 & $5.00(5.00)$ & \\
\hline Manual worker & $34(9.5)$ & 1.00 & 50.00 & $7.50(5.00)$ & \\
\hline Student & $25(7.0)$ & 2.00 & 50.00 & $5.00(1.00)$ & \\
\hline Housewife & $36(10.1)$ & 1.00 & 20.00 & $5.00(7.00)$ & \\
\hline Unemployed & $21(5.9)$ & 1.00 & 30.00 & $5.00(2.00)$ & \\
\hline Retired & $18(5.0)$ & 1.00 & 50.00 & $5.00(1.75)$ & \\
\hline Household Income (RM) & & & & & $0.014^{a}$ \\
\hline$<500$ & $9(2.5)$ & 1.00 & 50.00 & $5.00(5.00)$ & \\
\hline 500-999 & $57(15.9)$ & 1.00 & 100.00 & $10.00(7.50)$ & \\
\hline $1,000-1,999$ & $84(23.5)$ & 1.00 & 37.00 & $5.00(5.00)$ & \\
\hline$\geq 2,000$ & $163(45.5)$ & 1.00 & 50.00 & $5.00(5.00)$ & \\
\hline No income & $45(12.6)$ & 1.00 & 50.00 & $5.00(6.00)$ & \\
\hline Nature of pharmacies visited & & & & & $0.449^{a}$ \\
\hline Pharmacies in public facilities & $34(9.5)$ & 1.00 & 50.00 & $5.00(6.25)$ & \\
\hline Community pharmacies & $44(12.3)$ & 1.00 & 30.00 & $7.50(10.00)$ & \\
\hline Both & $280(78.2)$ & 1.00 & 100.00 & $5.00(5.00)$ & \\
\hline $\begin{array}{l}\text { Frequency of public pharmacy visits } \\
\text { Never }\end{array}$ & & & & & $0.337^{a}$ \\
\hline Once or more per week & $44(12.3)$ & 1.00 & 30.00 & $7.50(10.00)$ & \\
\hline $2-3$ times per month & $9(2.5)$ & 5.00 & 20.00 & $5.00(10.00)$ & \\
\hline Every few months & $62(17.3)$ & 1.00 & 50.00 & $5.00(5.00)$ & \\
\hline Once per year & $173(48.3)$ & 1.00 & 50.00 & $5.00(5.00)$ & \\
\hline & $70(19.6)$ & 1.00 & 100.00 & $5.00(5.00)$ & \\
\hline Frequency of community pharmacy visits & & & & & $0.040^{\mathrm{a}}$ \\
\hline Never & $34(9.5)$ & 1.00 & 50.00 & $5.00(6.25)$ & \\
\hline Once or more per week & $20(5.6)$ & 5.00 & 50.00 & $10.00(10.00)$ & \\
\hline $2-3$ times per month & $81(22.6)$ & 1.00 & 50.00 & $5.00(5.00)$ & \\
\hline Every few months & $176(49.2)$ & 1.00 & 100.00 & $5.00(5.00)$ & \\
\hline Once per year & $47(13.1)$ & 1.00 & 50.00 & $5.00(5.00)$ & \\
\hline
\end{tabular}

Notes: ${ }^{a}$ Kruskal-Wallis test, ${ }^{\mathrm{b}}$ Mann-Whitney test

\section{DISCUSSION}

This was the first multicentre study conducted among the general population in Sabah to evaluate the perceptions of the general public of the roles of pharmacists and the WTP for pharmacist-provided dispensing services. 


\section{Nature and Frequency of Pharmacy Service Utilisation}

The majority of the respondents in this study had visited pharmacies in both public facilities and community setting once every few months. This finding was different from most of the studies conducted in Asian and European countries, in which more than half of the respondents would visit a community pharmacy at least once per month (El Hajj, Salem and Mansoor 2011; Tang 2008). However, this comparison might not be valid due to the differences in healthcare systems in various countries, with some countries having already expanded the roles of pharmacists, while others had already implemented dispensing separation (Eades, Furguson and O'Carroll 2011). Hence, the frequency of patient visits to pharmacies in these countries was expected to be higher.

\section{Public Perceptions of the Roles of Pharmacists}

A majority of the respondents had no difficulty in distinguishing between pharmacists and other healthcare professionals. This finding corresponded to the result obtained from a study performed in Canada in which $68.2 \%$ of the respondents were able to differentiate between pharmacists and other healthcare professionals, such as doctors and nurses (Perepelkin 2011). In Malaysia, pharmacists in public facilities were normally seen in pharmacy departments and they could be easily differentiated from pharmacist assistants or trainees who were wearing grey uniforms. This distinction also applied to the private community pharmacies, where the staff other than the pharmacist on the premises normally wore uniforms. Moreover, some qualitative studies have also shown that pharmacists should wear a white coat so that they can be differentiated from other healthcare staff and to reflect a professional image (Rayes, Hassali and Abduelkarem 2014; Tang 2008).

Based on the results, a majority of the respondents agreed that pharmacists' main job was to help them to understand how to use their medications and to warn them of any possible side effects. In addition, they agreed that pharmacists knew more about their medications and side effects and how to use the medications than their doctors. In fact, Asians and Africans showed high respect for pharmacists as healthcare professionals. They agreed that pharmacists were well educated and understood medicines well (Tang 2008). A study conducted in Japan also showed that approximately half of the general public perceived pharmacists as drug experts (Tang 2008). Similar findings were also noted in studies conducted in the UK and Sweden (Tang 2008).

Despite being addressed as drug experts, more than half of the respondents in this study perceived that pharmacists' role was only to supply medications and also that the pharmacist's job was to follow doctors' directions. In addition, less than half of the respondents agreed that pharmacists were allowed to intervene and modify prescriptions and $12.4 \%$ of the respondents were not aware that pharmacists could play such a role. In fact, a study conducted in Vietnam showed that pharmacists were seen as doctors' assistants who followed doctors' instructions with limited personal initiatives (Tang 2008). Moreover, a study conducted in Taiwan showed that more than $79.6 \%$ of respondents viewed a pharmacist's responsibility as accurately dispensing medications as prescribed and nearly half of them felt that pharmacists should not intervene in doctors' prescriptions (Tang 2008). However, in most of the European countries, pharmacists' ability to countercheck prescriptions was highly appreciated. Moreover, many patients placed pharmacists between doctors and nurses, with pharmacists seen as doctors' assistants, but they were placed higher in the hierarchy than nurses to influence doctors' decisions (Tang 2008).

One of the important components of pharmaceutical care is medication counselling. In fact, pharmacists are professionally trained in the counselling of medications and medical 
devices and in disease management. Hence, pharmacist-provided medication counselling is important for improving medication use, preventing medication errors and ensuring that the desired outcomes can be achieved. Based on this study, almost $90 \%$ of the respondents appreciated and adhered to counselling points provided by their pharmacists. This finding corresponded with the results of a survey conducted in the USA, which showed that patients were becoming more willing to accept counselling provided by pharmacists (Eades, Ferguson and O'Carroll 2011). However, this finding was not the case in Taiwan, where doctors were still considered by the general public to be the most qualified healthcare professionals to provide drug information. This finding showed the poor recognition of pharmacists' competency among the Taiwanese population (Tang 2008).

It is an interesting finding that $85.0 \%$ of the respondents in this study hoped that pharmacists could play greater roles in healthcare in the future. This finding corresponded with findings obtained from several studies conducted in Asian countries, in which the public considered the current provision of non-drug services by pharmacists to be poor. The respondents expected that pharmacist-provided services should include more diverse non-drug services, such as health screening, medical testing, lifestyle promotion, provision of health education and first aid services (Tang 2008). However, a study conducted in Qatar showed that patients' expectations about the role of pharmacists were still mainly drug-based. More than $70 \%$ of the patients did not expect pharmacists to monitor their health progress or to perform any health screening (EI Hajj, Salem and Mansoor 2011). Conversely, pharmacists in the UK are required to provide public health services because the promotion of healthy lifestyles is one of the five core roles of pharmacists, as defined by the Royal Pharmaceutical Society of Great Britain (RPSGB). Based on studies conducted in various countries, some of the expected roles of pharmacists in public health services include smoking cessation counselling, the providing of health screening and weight management (Eades, Ferguson and O'Carroll 2011). However, the current study did not assess the expected, specific role expansion of pharmacists among respondents in Sabah. Perhaps future studies could be conducted to address this matter.

Forty percent of the respondents in this study agreed that community pharmacists were simply businesspeople who sold products in their pharmacies. This percentage was higher compared to Japan (11.8\%), Qatar (27.0\%), Canada $(12.4 \%)$ and Ireland $(32.0 \%)$ (El Hajj, Salem and Mansoor 2011; Perepelkin 2011; Tang 2008). Studies have shown that the public is worried that community pharmacists might be business-oriented and respondents anticipated that community pharmacists would achieve a balance between healthcare and business matters. They also demonstrated a strong desire for a shift of community pharmacies from business to healthcare aspects (Tang 2008). The high percentage observed among respondents in Sabah might have been due to the nonseparated prescribing/dispensing practices and the limited roles of community pharmacists in Malaysia. In addition, due to the community pharmacy setting, which resembles a sundry shop and it being common that consumer products that are non-health-related are sold in community pharmacies, it is inevitable that the public perceives community pharmacists to have a predisposition towards a business orientation rather than providing healthcare services.

\section{Factors Influencing Perceptions of Pharmacists}

Based on this study, the friendliness of pharmacists, their expertise, the environment and facility of the pharmacy and waiting times of less than 30 minutes all influenced the respondents' perceptions of pharmacists. Among these factors, waiting time was the least influential. Based on studies performed in countries, the factors influencing public perceptions 
of pharmacists were actually non-exhaustive. For example, pharmacists' attire, nationality and age were some of the important determinants of pharmacists by the general public in Dubai (Rayes, Hassali and Abduelkarem 2014). In Qatar, pharmacists' communication skills, medication knowledge, honesty and professionalism, their ability to understand patients' concerns and their ability to communicate in native languages were some of the important factors (EI Hajj, Salem and Mansoor 2011). In Japan, in contrast, politeness and willingness to listen, knowledge in understanding patients' psychology and feeling that pharmacists were more approachable were all important aspects and characteristics of pharmacists according to the general public (Tang 2008). Studies conducted in Canada and Scotland showed that expertise and helpfulness were important factors that influenced public perceptions of community pharmacists (Perepelkin 2011; Tang 2008).

Based on the key performance indicator of the Ministry of Health $(\mathrm{MOH})$ of Malaysia, all public healthcare facilities must dispense medications to patients within 30 minutes from the moment that the patient presents a prescription to the pharmacy. However, no such limit has been set for the community setting. Nevertheless, waiting times did not really influence the study respondents' perceptions of pharmacists in Sabah. However, a study conducted in Scotland showed that the public perceived a good pharmacist to be one who could perform quick dispensing (Tang 2008).

Since the factors influencing public perceptions of pharmacists are non-exhaustive, perhaps future studies using open-ended questions or qualitative approaches could be conducted to investigate this matter further.

\section{Access to Community Pharmacies}

Due to the extensive debates on dispensing separation and the expectation that more patients will visit community pharmacies if dispensing separation is implemented in Malaysia, we also assessed respondents' opinions about community pharmacies in this study. Based on the results, the expertise of pharmacists, the location of the community pharmacy and the attitudes of the pharmacist and staff were the top three factors influencing whether a respondent would visit a community pharmacy or not. The location of the pharmacy was an important factor, as proved by studies conducted in Dubai, Qatar and Japan (EI Hajj, Salem and Mansoor 2011; Rayes, Hassali and Abduelkarem 2014; Tang 2008), because the public perceived that a pharmacy located within the community and easily accessible could operate as the first provider in the healthcare system to address health-related problems. In addition, the public also does not have to travel a long distance to obtain its medications, which can reduce the unnecessary additional costs that might be incurred. As discussed in the previous section, the expertise of the pharmacist greatly influenced the public perceptions of him or her and hence also whether a patient chose to visit the community pharmacy or not. In fact, the main reasons for a patient to visit a community pharmacy are to purchase medications and to obtain professional advice on drug-and health-related issues. Hence, a pharmacy where the pharmacist demonstrates high expertise and professionalism would definitely be a choice. In a study conducted in Canada (Perepelkin 2011), the most important factor that influenced the choice of a community pharmacy by the public was how the pharmacist and other staff treated customers (93.1\%). The finding from a study conducted in Qatar also showed that $62.0 \%$ of the respondents agreed that the staff in their preferred pharmacy should be friendly. This finding is true because all patients want to be served politely and empathetically.

Based on this study, price did not really influence the choice of a particular community pharmacy because only $73.3 \%$ of the respondents agreed that community pharmacies offering lower prices would be their preference. This finding corresponded to 
study results from Qatar (43.0\%) and Canada (58.6\%) (EI Hajj, Salem and Mansoor 2011; Perepelkin 2011), which showed that the cost of prescriptions was the least influential factor in community pharmacy visits among all of the factors of consideration by the general public. This finding showed that the respondents were generally willing to spend more if their health conditions could be addressed effectively. It is also interesting to note that more than half of the respondents in this study felt that the business hours for community pharmacies from 8:00 a.m. to 5:00 p.m. were not sufficient. Studies conducted in Qatar and Japan showed that the majority of the respondents would prefer pharmacies in the country to operate during convenient working hours (El Hajj, Salem and Mansoor 2011; Tang 2008). However, the definition of "convenient working hours" was not defined clearly. In Malaysia, 8:00 a.m. to 5:00 p.m. are the standard working hours for most public and private agencies in the country and most of the community pharmacies in Malaysia do not operate after 6:00 p.m. Hence, these hours constitute one of the obstacles hindering patients from obtaining medications and healthcare advice from community pharmacies at night.

\section{Willingness to Pay (WTP) for Pharmacist-provided Dispensing Services}

Based on this study, $55.3 \%$ of the respondents were willing to pay for pharmacist-provided dispensing services. A similar study conducted in the state of Pulau Pinang, Malaysia, showed that $67.0 \%$ of the respondents were willing to pay for pharmacist-provided dispensing services (Shafie and Hassali 2010). The higher percentage recorded in the aforementioned study might have occurred because the state of Pulau Pinang is generally an urbanised and high-income state, whereas the socioeconomic status among the general public in the state of Sabah is generally lower than in the state of Pulau Pinang. Nevertheless, the results of this study are encouraging because they suggest that more than half of the respondents appreciated the importance of pharmacist-provided dispensing services and were willing to pay for the services.

Respondents' education levels, monthly household income, the nature of their pharmacies visits and the frequency of community pharmacy visits showed statistically significant associations with their WTP for pharmacist-provided dispensing services in this study. This finding contradicted those of the study conducted in the state of Pulau Pinang, Malaysia, which showed that none of these demographic factors were associated with the respondents' WTP (Shafie and Hassali 2010). Based on this study, it can be seen that those respondents with tertiary education levels were more willing to pay than those with only primary and secondary education levels. In addition, only $40.0 \%$ of respondents who had not attended school were willing to pay, likely because those with higher education levels understand pharmacists' roles and their importance in providing dispensing services better than those with lower education levels. However, this factor was not explored in the present study. Generally, those respondents who earned higher monthly household incomes in this study were willing to pay for pharmacist-provided dispensing services. This finding is understandable because those respondents who earned less might not be able to afford or feel comfortable to pay out-of-pocket for dispensing services that are currently free of charge. It is also interesting to note that almost two thirds of the respondents who had only visited pharmacies in public facilities were not willing to pay for pharmacist-provided dispensing services. In addition, the frequency of visits to pharmacies in public facilities did not influence the WTP either, likely because pharmacist-provided dispensing services in public facilities are currently free of charge; hence, patients do not see the rationale of imposing a fee on such services in the future. Finally, it is also noted that the more frequently that the respondents visited community pharmacies, the greater the likelihood was for them to pay for pharmacist-provided dispensing services, likely because those who 
had visited community pharmacies frequently had a better understanding and appreciation of community pharmacists' roles and hence were more willing to pay for the services.

In a study conducted in the state of Pulau Pinang (Shafie and Hassali 2010), the societal value of the pharmacist-provided dispensing services was RM10.00, based on the initial dispensing cost analysis; hence, RM10.00 was used as the initial bidding value in that study. However, considering the lower socioeconomic status among the general public in the state of Sabah compared to that in the state of Pulau Pinang, RM5.00 was chosen as the initial bidding value for this study. The amount is reasonable because it is similar to the charge of RM5.00 for every specialist clinic review in public healthcare facilities in Malaysia.

The city of residence, occupation, monthly household income and frequency of community pharmacy visits showed statistically significant associations with the amount that the respondents were willing to pay for pharmacist-provided dispensing services in this study. This finding contradicted those of a study conducted in the state of Pulau Pinang, Malaysia, which showed that none of the demographic factors were associated with the amounts that the respondents were willing to pay (Shafie and Hassali 2010). In fact, some studies have demonstrated significant relationships between factors such as the age of participants and their incomes with the amounts that they were willing to pay (Shafie and Hassali, 2010). Although the four factors in this study were significantly associated with the amount that the respondents were willing to pay, the associations were very inconsistent, likely because the pharmacist-provided dispensing fee is a new concept to the Malaysian public and Malaysian people are unable to value the service and hence unable to determine what amount to pay for it.

\section{Limitations of This Study and Future Recommendations}

This study had several limitations. Firstly, the interview method was used in this study; hence, there might be the possibility of respondent bias because the respondents might not have accurately expressed their perceptions in their responses. Secondly, this study was conducted in the state of Sabah only, with only the involvement of the three major cities in the state. Hence, the perceptions of the respondents towards the role of pharmacists might not reflect the general perceptions of the Malaysian population.

In terms of WTP, the state of Sabah is generally a middle-income state and it has a lower socioeconomic status than its counterparts in Peninsular Malaysia. In addition, we only obtained samples from three main cities in Sabah and not from the interior rural populations. Hence, the WTP and the amounts obtained from this study might not reflect the general situation in the whole of Malaysia. Perhaps future studies should involve all of the states in Malaysia to obtain more generalisable results. Secondly, dispensing separation was only a hypothetical scenario in this study and the mechanism of payment for pharmacist-provided dispensing services was not mentioned in this study. These factors might have influenced the respondents' WTP due to hypothetical bias because some of them might not have been able to visualise the real scenario and some of them might have believed that social health insurance should cover the fees incurred, like in other countries (Wedgwood and Sansom 2003). Hence, future studies should include more relevant information, such as a description of the mechanism of payment, to reduce strategic and information biases (Wedgwood and Sansom 2003).

The amount that the respondents were willing to pay was subject to starting point bias, which is the starting price for the bidding that influences the final agreed amount (Wedgwood and Sansom 2003). It was found that majority of the respondents in this study $(42.5 \%)$ agreed to pay RM5.00, which was the starting price provided to the respondents. In addition, even if a respondent agreed to pay a certain amount in this study, it does not

Malay J Pharm Sci, Vol. 16, No. 1 (2018): 1-21 
indicate he or she would do so in the future because the real-life scenario might be different and this would influence the WTP amount. To solve these problems, perhaps the starting price could be varied to examine whether it influenced the final agreed-upon amount in future studies.

\section{CONCLUSION}

This study provided valuable findings regarding the public perceptions of the role of pharmacists in the state of Sabah, Malaysia. It appears that the respondents in this study appreciated the roles of pharmacists. However, the roles of pharmacists were mainly viewed as assisting prescribers and other drug-related responsibilities. Most respondents would like pharmacists to expand their existing roles in healthcare settings. In addition, community pharmacists were viewed as business-oriented in Sabah. In addition, most of the respondents would like community pharmacies to be open for extended hours for their availability. Hence, to improve pharmacy practice, especially in the community setting, efforts should be undertaken to address the respondents' misunderstandings of the pharmacy profession and to promote the roles of pharmacists to the general public.

It was also found that more than half of the public in the state of Sabah valued pharmacist-provided dispensing services and was willing to pay RM5.00 for the services in general. However, whether the public understanding of pharmacist-provided dispensing services influenced the WTP and its amount was not assessed in this study. Nevertheless, providing education to the public regarding the roles of pharmacists in dispensing services is important to enlighten the public and to improve the public acceptance of such practices, which will be implemented in the near future.

\section{ACKNOWLEDGEMENTS}

The author would like to thank the Director General of Health of Malaysia for the permission to publish this paper. The author would also like to express his gratitude to the Pharmaceutical Services Division, Sabah State Health Department, Sabah Pharmaceutical Society, the hospital directors or heads and the chief pharmacists or pharmacists-in-charge of the respective facilities for their support in this study. The author would also like to thank the following pharmacists who participated as data collectors in this study: Melissa Mejin (Queen Elizabeth Hospital, Kota Kinabalu); Mahmud Majdi Mahmud Saedon, Mohammad Fikkiruddin Jamsari (Queen Elizabeth II Hospital, Kota Kinabalu); Hui Jun Hoe, Michelle Yong Li Sian, Yazmin Hawa binti Abd Rashid (Sabah Women and Children Hospital, Kota Kinabalu); Aishah Mohd Shah (Mesra Bukit Padang Hospital, Kota Kinabalu); Nurul Nasrah Mohd Ariffin, Roselyne John Han (Kota Kinabalu Regional Health Office); Amelia Ambrose (Kota Kinabalu Pharmacy Enforcement Branch); Fia Iskandar, Gopi Muniandy, Ong It Seang (Pharmaceutical Services Division, Sabah State Health Department); Chan Weng Loong, Ibrohem Syamil Rosli, Lee Chon Hong, Lee Yee Lin, Wong Wei Wei (Duchess of Kent Hospital, Sandakan); Jennifer Audrey Mabeng, Lee Hooi Peng (Sandakan Regional Health Office); and Choong Yunn Er, Hazlinda Mohamad, Lau Mei Mei, Liew Shek Yee, Melissa Lim Ven Ching, Mohamad Fitri Md Zuberi, Pang Yih Fui, Tan Yui Ping, Wong Jing Ting (Hospital Tawau). The author would also like to express his gratitude to Tan Yui Ping and Aishah Mohd Shah for their assistance in preparing the study protocol and to Liau Siow Yen, Narwani Hussin, Sharon Linus Lojikip, Lim Wei Yin and Ooi Qing Xi for their guidance and effort in reviewing the study protocol. 


\section{REFERENCES}

EADES, C. E., FERGUSON, J. S. \& O'CARROLL, R. E. (2011) Public health in community pharmacy: A systematic review of pharmacist and consumer views, BMC Public Health, 11: 582. https://doi.org/10.1186/1471-2458-11-582.

EL HAJJ, M. S., SALEM, S. \& MANSOOR, H. (2011) Public's attitudes towards community pharmacy in Qatar: A pilot study, Patient Preference and Adherence, 5: 405-422. https:// doi.org/10.2147/PPA.S22117.

HASSALI, M. A., AWAISU, A., SHAFIE, A. A. \& SAEED, M. S. (2009) Professional training and roles of community pharmacists in Malaysia: Views from general medical practitioners, Malaysian Family Physician, 4(2-3): 71-76.

HUTTIN, C. (1996) A critical review of the remuneration systems for pharmacists, Health Policy, 36(1): 53-68. https://doi.org/10.1016/0168-8510(95)00796-2.

PEREPELKIN, J. (2011) Public opinion of pharmacists and pharmacist prescribing, Canadian Pharmacists Journal, 144(2): 86-93. https://doi.org/10.3821/1913-701X-144.2.86.

RAYES, I. K., HASSALI, M. A. \& ABDUELKAREM, A. R. (2014) A qualitative study exploring public perceptions on the role of community pharmacists in Dubai, Pharmacy Practice, 12(1): 363. https://doi.org/10.4321/S1886-36552014000100005.

SAW, P. S., NISSEN, L. M., FREEMAN, C., WONG, P. S. \& MAK, V. (2015) Health care consumers' perspectives on pharmacist integration into private general practitioner clinics in Malaysia: A qualitative study, Patient Preference and Adherence, 9: 467-477. https://doi. org/10.2147/PPA.S73953.

SHAFIE, A. A. \& HASSALI, M. A. (2011) Community pharmacy dispensing costs in the state of Penang, Malaysia, Journal of Applied Pharmaceutical Sciences, 1(6): 143-145.

SHAFIE, A. A. \& HASSALI, M. A. (2010) Willingness to pay for a pharmacist's dispensing service: A cross-sectional pilot study in the state of Penang, Malaysia, Pharmacy Practice, 8(2): 116-121. https://doi.org/10.4321/S1886-36552010000200006.

SHAFIE, A. A., HASSALI, M. A., AZHAR, S. \& SEE, O. G. (2012) Separation of prescribing and dispensing in Malaysia: A summary of arguments, Research in Social and Administrative Pharmacy, 8(3): 258-262. https://doi.org/10.1016/j.sapharm.2011.06.002.

Malay J Pharm Sci, Vol. 16, No. 1 (2018): 1-21 
TANG, J. T. T. (2008) The role of pharmacists in Asia and Africa: A comparative study to the UK and Sweden, diss., Uppsala University. http://www.farmfak.uu.se/farm/exjob/ diplomawork/HT08_JanetT_apotekarens_roll_i_fyra_lander.pdf (27 October 2013).

TOOTELIAN, D. H., ROLSTON, L. W. \& NEGRETE, M. J. (2005) Consumer receptiveness to non-traditional roles for community pharmacists, Health Markerting Quartely, 23(1): 4356. https://doi.org/10.1300/J026v23n01_04.

WEDGWOOD, A. \& SANSOM, K. (2003) Willingness-to-pay surveys: A streamlined approach; Guidance notes for small town water services, pp. 51-55 (Loughborough: Water, Engineering and Development Centre, Loughborough University). http://www.wsp.org/ Hygiene-Sanitation-Water-Toolkit/Resources/Readings/Willingness\%20to\%20Pay.pdf (3 November 2013). 